\title{
BASAL CARDIAC FUNCTION AND BODY COMPOSITION WITH SPECIAL REFERENCE TO OBESITY ${ }^{1}$
}

\author{
By HENRY LONGSTREET TAYLOR, JOSEF BROZEK, AND ANCEL KEYS with the \\ TECH NICAL ASSISTANCE OF WALTER CARLSON
}

(From the Laboratory of Physiological Hygiene, University of Minnesota, Minneapolis, Minn.)

(Submitted for publication July 14, 1952; accepted August 9, 1952)

It has been known for many years that the surface area is increased with increasing obesity and that this increase in surface area is accompanied by a proportional increase in basal oxygen consumption (1). Therefore, it has been reasoned that in the presence of obesity cardiac output and cardiac work in the basal state are increased approximately in proportion to the increase in oxygen consumption (2). This reasoning is based on the assumption that the quantity of oxygen carried away by a liter of blood from the lungs (the arteriovenous oxygen difference) is constant in lean and obese individuals.

Certain generally accepted facts support this argument. Thus it is generally agreed that basal cardiac output is proportional to surface area and oxygen consumption. The relationship between surface area and cardiac output has been re-examined in a recent publication from this laboratory (3) and it was found that as a first approximation, the cardiac output is directly proportional to surface area. However, the individual differences in surface area accounted for only 40 per cent of the individual differences in cardiac output. Furthermore, it has been found that while resting cardiac output is proportional to oxygen consumption; the individual differences in oxygen consumption account for only 50 per cent of the observed variability in cardiac output (4). It is clear then that factors other than body size as measured by the surface area or oxygen consumption influence the basal cardiac output. Among the several factors which could account for the unexplained variability is body composition, particularly the fat content of the body. It is known that fat tissue has a metabolism (5) but nothing is known regarding the arteriovenous oxygen differ-

1 This investigation was supported (in part) by a research grant H-10(C5) from the National Heart Institute, of the National Institutes of Health, Public Health Service. ence of blood flowing through fatty tissues or the rate at which it flows.

Precise investigation of the relationships between cardiac function and obesity has been hampered by the inability of the investigator to estimate the relative amounts of fat and other tissue in a given individual. The use of the specific gravity of the body to estimate the relative amount of fat in intact man (6) makes such investigations profitable. It is the purpose of this paper to examine the quantitative relationships between cardiac output, cardiac work and the arteriovenous difference on the one hand and the fat content of the body on the other.

\section{SUBJECTS AND CONDITIONS}

The subjects used in this investigation were 34 male university students, 18 to 31 years old, who were free of disease detectable by physical examination. Deliberate efforts were made to obtain a scattering of men from very fat to very lean. The men reported to the laboratory in the morning without breakfast or late in the afternoon without lunch. They rested for one half hour before observations were made. All procedures were carried out in an air-conditioned room. Duplicate determinations of cardiac output were made at one sitting. This was followed by a measurement of the intra-arterial blood pressure. The specific gravity of the body and a roentgenogram of the chest were made after the other cardiovascular measurements had been carried out. In 22 of the 34 subjects, duplicate cardiac output determinations were made on two separate days. Intraarterial pressures were obtained on 20 subjects and roentgenograms of the chest on 15 .

\section{METHODS}

The cardiac output measurements were made with the acetylene technic of Grollman. The final calculations were carried out with the corrections worked out by Chapman and his associates (7) to bring the values into 
line with those of the direct Fick (catheter) method. Intra-arterial pressures were measured with a strain gauge and a Cournand needle. The complete recording system was so adjusted that it would pass a square wave of $300 \mathrm{~mm}$. $\mathrm{Hg}$ in 0.02 second with a 5 per cent overshoot beyond the base line. Static calibrations were carried out with each determination. The specific gravity of the body was determined from the weight of the individual in water and in air. The volume of residual air in the lung was determined while the men were being weighed under water so that a simultaneous determination of weight under water and residual volume was obtained. The method of Cournand and his co-workers was employed for the measurement of lung volume (8). The details of the weighing procedure have been reported elsewhere (9). In those cases in which measurements of residual volume were not made, a standard correction of
1,500 cc. was applied. The per cent of body weight represented by fat was calculated from tables given by Rathbun and Pace (10). The size of the heart was calculated from measurements of the area of the cardiac shadow on a six-foot roentgenogram of the chest by the method of Keys and his associates (11). The mean arterial pressures were obtained by integrating the recorded pulse wave with a planimeter. The cardiac work was calculated as the mean arterial pressure $X$ the cardiac output, and the kinetic energy component was calculated using the aortic sizes given by Bazett and his group (12). Surface area was calculated according to the procedure of Du Bois.

\section{RESULTS}

The data for the individual subjects are presented in Table I. The cardiac outputs in liters

TABLE I

The anthropometric characteristics and cardiac output along with related measures of cardiovascular function of 34 young men*

\begin{tabular}{|c|c|c|c|c|c|c|c|c|c|c|c|c|}
\hline Subject & Age & Height & Weight & S. A. & $\%$ Fat & Fat & L. B. M. & $\begin{array}{l}\text { Cardiac } \\
\text { output }\end{array}$ & $A-V$ & B. $P$. & $\begin{array}{c}\text { Cardiac } \\
\text { vol. }\end{array}$ & $\begin{array}{c}\text { Resid. } \\
\text { lung vol. }\end{array}$ \\
\hline $\begin{array}{l}\text { Nay } \\
\text { CVD } 56 \\
\text { Eric } \\
\text { CVD } 104 \\
\text { Scan. } \\
\text { Alt. } \\
\text { Will. } \\
\text { CVD } 3 \\
\text { Koch. } \\
\text { CVD } 7 \\
\text { Ott. } \\
\text { Ort. } \\
\text { Lin. } \\
\text { CVD } 17 \\
\text { Traut } \\
\text { Torg. } \\
\text { Fors. } \\
\text { Stra. } \\
\text { Podem. } \\
\text { CVD } 120 \\
\text { CVD } 119 \\
\text { CVD } 101 \\
\text { CVD } 162 \\
\text { Donal. } \\
\text { CVD } 41 \\
\text { Svie. } \\
\text { CVD } 13 \\
\text { CVD } 110 \\
\text { Adam. } \\
\text { CVD } 31 \\
\text { Erwi. } \\
\text { Teit. } \\
\text { Chri. } \\
\text { Duc. }\end{array}$ & $\begin{array}{l}28 \\
24 \\
20 \\
23 \\
19 \\
20 \\
20 \\
25 \\
24 \\
25 \\
31 \\
20 \\
21 \\
22 \\
22 \\
24 \\
29 \\
21 \\
23 \\
24 \\
20 \\
21 \\
24 \\
25 \\
25 \\
25 \\
22 \\
20 \\
23 \\
26 \\
27 \\
19 \\
21 \\
24\end{array}$ & $\begin{array}{l}165 \\
169 \\
178 \\
162 \\
182 \\
169 \\
176 \\
179 \\
175 \\
167 \\
173 \\
166 \\
175 \\
181 \\
179 \\
178 \\
176 \\
171 \\
173 \\
176 \\
177 \\
185 \\
181 \\
184 \\
170 \\
179 \\
177 \\
175 \\
172 \\
175 \\
184 \\
189 \\
179 \\
184\end{array}$ & $\begin{array}{r}53.68 \\
51.80 \\
54.52 \\
53.10 \\
53.73 \\
71.93 \\
62.00 \\
58.60 \\
76.40 \\
67.00 \\
86.00 \\
80.15 \\
62.20 \\
69.20 \\
69.60 \\
75.60 \\
65.20 \\
72.10 \\
87.27 \\
79.32 \\
71.80 \\
70.60 \\
73.70 \\
70.40 \\
76.50 \\
77.40 \\
70.10 \\
87.57 \\
76.20 \\
95.30 \\
101.43 \\
84.40 \\
84.00 \\
132.50\end{array}$ & $\begin{array}{l}1.58 \\
1.58 \\
1.69 \\
1.56 \\
1.72 \\
1.83 \\
1.73 \\
1.74 \\
1.92 \\
1.74 \\
2.02 \\
1.89 \\
1.75 \\
1.88 \\
1.87 \\
1.94 \\
1.80 \\
1.84 \\
2.04 \\
1.94 \\
1.89 \\
1.92 \\
1.93 \\
1.92 \\
1.87 \\
1.96 \\
1.86 \\
2.00 \\
1.89 \\
2.10 \\
2.23 \\
2.10 \\
2.02 \\
2.53\end{array}$ & $\begin{array}{r}17.5 \\
5.0 \\
8.4 \\
1.3 \\
1.8 \\
22.0 \\
7.4 \\
1.4 \\
24.0 \\
11.2 \\
29.6 \\
24.0 \\
0.4 \\
9.3 \\
8.8 \\
15.6 \\
1.8 \\
10.7 \\
26.0 \\
18.5 \\
9.8 \\
7.0 \\
10.8 \\
6.9 \\
13.6 \\
14.6 \\
3.7 \\
22.5 \\
8.8 \\
24.5 \\
26.5 \\
7.4 \\
4.1 \\
33.7\end{array}$ & $\begin{array}{r}9.4 \\
2.6 \\
4.6 \\
0.7 \\
1.0 \\
15.8 \\
4.6 \\
0.8 \\
18.3 \\
7.5 \\
25.5 \\
19.2 \\
0.2 \\
6.4 \\
6.1 \\
11.8 \\
1.2 \\
7.7 \\
22.7 \\
14.7 \\
7.0 \\
4.9 \\
8.0 \\
4.9 \\
10.4 \\
11.3 \\
2.6 \\
19.7 \\
6.7 \\
23.3 \\
26.9 \\
6.2 \\
3.4 \\
44.6\end{array}$ & $\begin{array}{l}44.6 \\
49.2 \\
49.9 \\
52.4 \\
52.8 \\
56.1 \\
57.4 \\
57.8 \\
58.1 \\
59.5 \\
60.5 \\
60.9 \\
62.0 \\
62.8 \\
63.5 \\
63.8 \\
64.0 \\
64.4 \\
64.6 \\
64.6 \\
64.8 \\
65.7 \\
65.7 \\
65.5 \\
66.1 \\
66.1 \\
67.5 \\
67.9 \\
69.5 \\
72.0 \\
74.6 \\
78.2 \\
80.6 \\
87.8\end{array}$ & $\begin{array}{l}4.08(4) \\
3.79(2) \\
5.02(4) \\
5.23(2) \\
5.63(3) \\
4.60(4) \\
5.99(4) \\
5.63(2) \\
4.72(4) \\
4.15(2) \\
4.48(4) \\
4.78(4) \\
4.92(2) \\
5.94(2) \\
5.90(4) \\
5.68(4) \\
5.41(4) \\
6.08(4) \\
4.93(4) \\
5.88(2) \\
6.03(2) \\
5.50(2) \\
5.48(4) \\
5.87(4) \\
4.40(2) \\
6.88(4) \\
5.58(2) \\
5.83(4) \\
6.43(4) \\
6.64(2) \\
5.83(4) \\
6.52(4) \\
7.22(4) \\
7.35(4)\end{array}$ & $\begin{array}{l}53 \\
53 \\
43 \\
44 \\
34 \\
43 \\
34 \\
37 \\
46 \\
53 \\
51 \\
52 \\
42 \\
37 \\
38 \\
47 \\
39 \\
40 \\
46 \\
43 \\
37 \\
44 \\
45 \\
41 \\
46 \\
37 \\
40 \\
41 \\
34 \\
38 \\
41 \\
40 \\
31 \\
41\end{array}$ & $\begin{array}{r}89 \\
76 \\
62 \\
83 \\
68 \\
\\
101 \\
\\
87 \\
72 \\
\\
97 \\
87 \\
90 \\
100 \\
80\end{array}$ & $\begin{array}{l}410 \\
674 \\
\\
574 \\
\\
615 \\
727 \\
478\end{array}$ & $\begin{array}{l}1.001 \\
1.866 \\
2.055 \\
1.296 \\
1.727 \\
1.115 \\
1.118 \\
0.980 \\
\\
1.191 \\
1.283 \\
2.498 \\
1.125 \\
1.182\end{array}$ \\
\hline $\begin{array}{l}\text { Mean } \\
\text { S.D. }\end{array}$ & $\begin{array}{c}23.1 \\
2.91\end{array}$ & $\begin{array}{r}175.9 \\
6.2\end{array}$ & $\begin{array}{l}74.16 \\
15.87\end{array}$ & $\begin{array}{l}1.89 \\
0.19\end{array}$ & $\begin{array}{r}12.90 \\
9.22\end{array}$ & $\begin{array}{r}10.61 \\
9.73\end{array}$ & $\begin{array}{r}63.56 \\
8.70\end{array}$ & $\begin{array}{l}5.54 \\
0.87\end{array}$ & $\begin{array}{r}42.1 \\
5.8\end{array}$ & & & \\
\hline
\end{tabular}

* Abbreviations and units: Age, in years; Height, in cm.; Weight, wt. of whole body in kg.; S.A., surface area in square meters; \% Fat, fat as per cent of whole body weight; Fat, weight in kgs.; L. B. M., lean body mass (body weight minus weight of fat) in kg.; Cardiac output, liters per minute, the number in parenthesis refers to the number of $\mathrm{C}$. O. determinations that were performed; A-V, the arteriovenous oxygen difference in cc. per liter of blood; B.P., the mean intraarterial blood pressure in mm. of $\mathrm{Hg}$.; Cardiac vol., the volume of the heart in cc.; Resid. lung vol., the residual volume of the lungs in cc. 


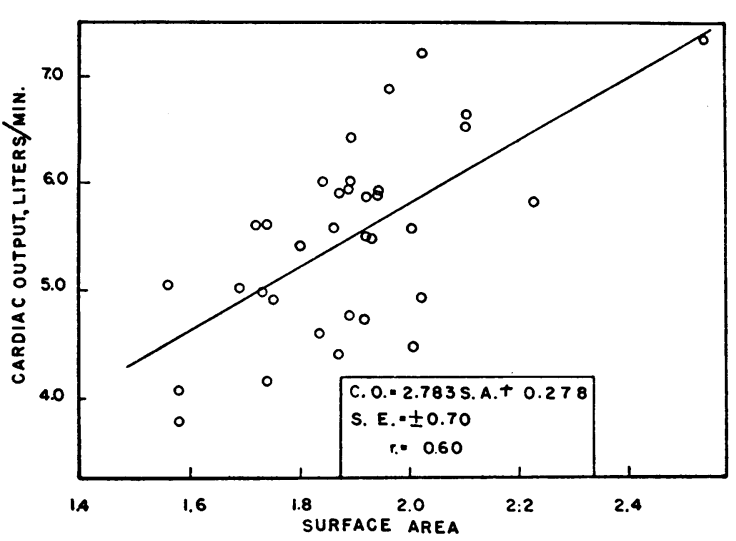

Fig. 1. The Relationship Between Cardiac Output in Liters per Minute and Surface Area in Square Meters in 34 Healthy Young Men

per minute are the mean values of the designated number of determinations. The values for the weight of lean body mass were obtained by subtracting the weight of fat from the total body weight. Since the constants for converting specific gravity to per cent of fat were derived from the weight of fat extracted by fat solvents from guinea pig carcasses (10) this value is equivalent to the lean tissue mass and theoretically includes any water and salt which may be present in the fatty tissues. In addition, the calculated value of fat is subject to such errors as may arise from assuming a constant specific gravity for the lean body mass.

\section{Cardiac output and body composition}

The correlations between important cardiovascular characteristics and the various measures of body size and composition have been calculated and are presented in Table II, along with other pertinent correlations. Significant correlations were found between cardiac output and body weight, surface area, and lean body mass, but no significant relationship was demonstrated between cardiac output and weight of body fat or per cent of body fat.

The data relating cardiac output to surface area and lean body mass are plotted in Figures 1 and 2 . The regression equations relating cardiac output with these two variables are given below:

Equation 1. C. O. $=2.783$ S. A. +0.278

Equation 2. C. O. $=0.074$ (L. B. M.) +0.838 ,

where cardiac output (C. O.) is expressed as liters
TABLE II

Coefficients of correlation ( $\mathrm{r}$ ) between cardiac output in liters per minute, arteriovenous oxygen difference $(A-V)$ in

cc. per liter, cardiac work in kilogram meters per minute, total peripheral resistance (T.P.R.) in dynes $\mathrm{cm} .^{-5}$ seconds and the several measures of body size and composition

\begin{tabular}{l|c|r|r|r|r|r}
\hline \hline \multicolumn{1}{c|}{ Measurement } & $\begin{array}{c}\text { No. of } \\
\text { subjects }\end{array}$ & $\begin{array}{c}\text { Body } \\
\text { weight }\end{array}$ & $\begin{array}{c}\text { Surface } \\
\text { area }\end{array}$ & $\begin{array}{r}\text { Per cent } \\
\text { fat }\end{array}$ & $\begin{array}{l}\text { Fat, } \\
\text { Kg. }\end{array}$ & $\begin{array}{l}\text { Lean } \\
\text { body } \\
\text { mass, } \\
\text { Kg. }\end{array}$ \\
\hline Cardiac output & 34 & 0.52 & 0.60 & -0.01 & 0.16 & 0.75 \\
A-V & 34 & 0.17 & -0.22 & 0.35 & 0.22 & -0.43 \\
Cardiac work & 20 & 0.50 & 0.55 & -0.13 & 0.07 & 0.76 \\
T.P.R. & 20 & 0.09 & 0.18 & 0.27 & 0.07 & -0.22 \\
\hline
\end{tabular}

For 34 subjects $r$ is significantly different from zero at the $5 \%$ level of probability if $r=0.34$ and at the $1 \%$ level if $r=0.44$. For 20 subjects similar values of $r$ are 0.44 and 0.56 , respectively.

per minute, surface area (S. A.) in square meters, and lean body mass (L. B. M.) in kilograms. The standard error of estimate of Equation 1 is 0.70 liters per minute, and that of Equation 2 is 0.58 . The basal cardiac output can therefore be predicted most accurately from the lean body mass.

Only a small advantage in prediction was found when multiple regression equations were used. The two most successful combinations are presented below :

Equation 3. C. O. $=0.061$ (L. B. M.)

Equation 4. C. O. $=0.084$ (L. B. M.) +0.034 height -4.313 -0.02 (fat weight) +0.415 ,

where height is expressed in centimeters and fat and lean body mass in kilograms.

For Equation 3, the coefficient of multiple cor-

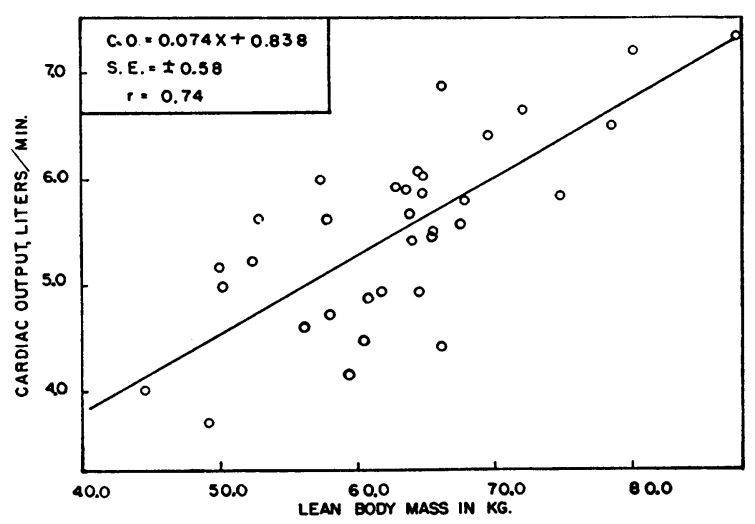

Fig. 2. The Relationship Between Cardiac Output in Liters per Minute and Lean Body Mass in Kilograms in 34 Healthy Young MeN 
relation relating the predicted cardiac output with the observed was found to be 0.77 while that for Equation 4 was 0.78 . The standard errors of estimate when rounded off to two places were 0.55 liters per minute for both equations.

It will be noted that Equation 2 assumes a linear relationship between the weight of a part of the body and cardiac output. However, it is known that total body weight raised to the $3 / 4$ power (a curvilinear relationship) is more closely related to oxygen consumption than is the linear regression equation (13). It is of interest then to examine the relationship of cardiac output and lean body mass raised to the power which provides the best fit. The regression equation between the $\log$ of the cardiac output and the log of the lean body mass yields the following power equation:

$$
\text { Equation 5. C. O. }=0.167 \text { (L. B. M.) } 0.842 \text {. }
$$

The coefficient of correlation relating the logarithms of cardiac output and lean body mass was found to be 0.73 or of the same order of magnitude as that found in the linear relationship. It appears then that there is no special advantage in the power equation over the linear equation.

\section{The arteriovenous oxygen difference and body composition.}

The coefficients of correlation between the arteriovenous oxygen difference and the various measures of body size and composition are included in Table II. There are two correlation coefficients which are significantly different from zero. A positive correlation coefficient of 0.35 ( $p<$ 0.05 ) between arteriovenous oxygen difference and percentage of fat in the body suggests a specific effect of fat. A negative correlation between the arteriovenous oxygen difference and lean body mass of $-0.43(p<0.02)$ indicates that the lean body mass is a more important determining factor. Neither of these relationships are good enough to suggest that they be used as reference points for predicting arteriovenous oxygen differences. However, we may examine multiple regression equations and here we find more useful correlations.

The relationships between cardiac output and measures of fat and lean body mass are given below :

Equation 6. $\mathrm{A}-\mathrm{V} \mathrm{O}_{2}=61.73+0.321$ (per cent of fat) -0.374 (L. B. M.)

Equation 7. $\mathrm{A}-\mathrm{V} \mathrm{O}_{2}=66.52+0.310$ (wt. of fat) -0.436 (L. B. M.),

where all weights are expressed in kilograms, the percentage of fat is the percentage of fat in the total body and the arteriovenous oxygen difference is in cc. of oxygen per liter of blood. The correlation coefficient relating the predicted and observed values of arteriovenous oxygen difference for Equation 6 is 0.65 and for Equation 7 is 0.63 whereas the standard errors of estimates are 0.78 and $0.80 \mathrm{cc}$. of oxygen per liter of blood, respectively. Both these correlations are significantly different from zero at the 1 per cent level. They are of the same order of magnitude as the correlation coefficients relating surface area and cardiac output, which range between 0.5 and 0.6 (3) and must be considered to have real biological meaning.

\section{Cardiac work and peripheral resistance}

Data from which basal cardiac work and total peripheral resistance could be calculated were obtained on 20 men. The means and standard deviations of the cardiac work and total peripheral resistance along with the figures for the several measures of body size and composition are presented in Table III while the correlation coefficients have been given in Table II. It is apparent that the total peripheral resistance is unrelated to any measure of body size or body composition. On the other hand, basal cardiac work is correlated with total body weight, surface area, and lean body mass. As in the case of the cardiac out-

TABLE III

The means and standard deviations of the cardiac work in kilogram meters per minute, the total peripheral resistance in dynes $\mathrm{cm} .^{-5}$ seconds, and the several items of body size and composition in 20 young men

\begin{tabular}{c|c|c|c|c|c|c|c}
\hline \hline & Cardiac work & T.P.R. & Body wt., Kg. & S.A. & Per cent fat & Fat, Kg. & $\begin{array}{c}\text { Lean body mass, } \\
\text { Kg. }\end{array}$ \\
\cline { 1 - 3 } Mean & 6.52 & $1,282.4$ & 75.34 & 1.91 & 14.19 & 11.65 & 63.70 \\
S.D. & 1.57 & 236.6 & 16.93 & 0.19 & 9.44 & 10.45 & 10.12 \\
\hline
\end{tabular}


TABLE IV

The values of the regression coefficients and the standard errors of estimates of the regression equation relating cardiac work in kilogram meters per minute to measurements of body size and composition

\begin{tabular}{l|c|r|r|r|r}
\hline & $\begin{array}{c}\text { Body } \\
\text { weight }\end{array}$ & $\begin{array}{c}\text { Surface } \\
\text { area }\end{array}$ & $\begin{array}{c}\text { Per cent } \\
\text { fat }\end{array}$ & Fat, Kg. & $\begin{array}{r}\text { Lean body } \\
\text { mass, Kg. }\end{array}$ \\
\hline$b^{*}$ & 0.046 & 4.44 & -0.02 & 0.01 & 0.12 \\
$a$ & 3.035 & -1.97 & 6.84 & 6.40 & -1.01 \\
S.E. & 1.361 & 1.31 & 1.55 & 1.57 & 1.02 \\
\hline
\end{tabular}

* $a$ and $b$ are defined by the following equation:

$$
y=a+b x,
$$

where $y$ is the predicted value and $x$ is the reference point.

put, the highest correlation was found between lean body mass and cardiac work. The regression coefficients from which one may construct the regression equations relating cardiac work with the several measures of body size and composition are presented in Table IV.

Estimates of the volume of the heart were obtained in 16 subjects. The relationships between cardiac work per cc. of heart volume and body composition were examined. The largest correlation coefficient found was 0.42 which existed between the percentage of fat in the body and the cardiac work per cc. of heart volume. But this value of $r$ would have to reach $0.50(p=0.05)$ before it could be considered significant. The relationships between heart volume and body composition will be discussed elsewhere.

\section{Anthropometric types and cardiovascular func- tions}

Equations 6 and 7 make it clear that different proportions of fat and lean body mass will have definite consequences in cardiovascular function. To illustrate these effects in more detail we have plotted the weight of fat against the lean body mass in Figure 3. The vertical line on the figure indicates the mean of the lean body mass in the group under study and the horizontal line is drawn through the mean of fat weights. The box in the center outlined by the dotted lines encloses an arbitrarily chosen "normal" group. The group in the lower left-hand quadrant is considered to to be low in lean body mass and low in fat; the group in the upper left-hand quadrant, high in fat and low in lean body mass; the group in the upper right-hand quadrant, high in fat and in lean body mass; whereas the group in the lower right-hand quadrant is high in lean body mass and low in fat. The characteristics of the five groups are presented in Table V. Inspection of the data reveals that those persons with a small lean body mass and a large weight of fat have high arteriovenous oxygen differences and those with a large lean body mass and only small amounts of fat have low arteriovenous oxygen differences.

The application of the usual $t$ test demonstrated that the mean arteriovenous oxygen differences were significantly different at the 5 per cent level for the following two pairs: 1 ) "normal" vs. high fat, low lean body mass, 2) high fat, low lean body mass vs. high fat, high lean body mass. In addition, a significant difference at the 1 per cent level was found between the means of the arteriovenous oxygen differences in the following pair : 1) high fat, low lean body mass vs. low fat, high lean body mass. The differences between the cardiac indexes were also found to be significant between the same pairs of groups. However, in the case of this variable it was shown that the cardiac index of the group with high fat, low lean body mass differed significantly from that with low fat, low lean body mass. None of the groups showed any significant differences in the cardiac output per kilogram of lean body mass.

Other methods of defining anthropometric categories may be employed. We have plotted the weight of fat per unit of height against the lean body mass per unit of height. The means of each

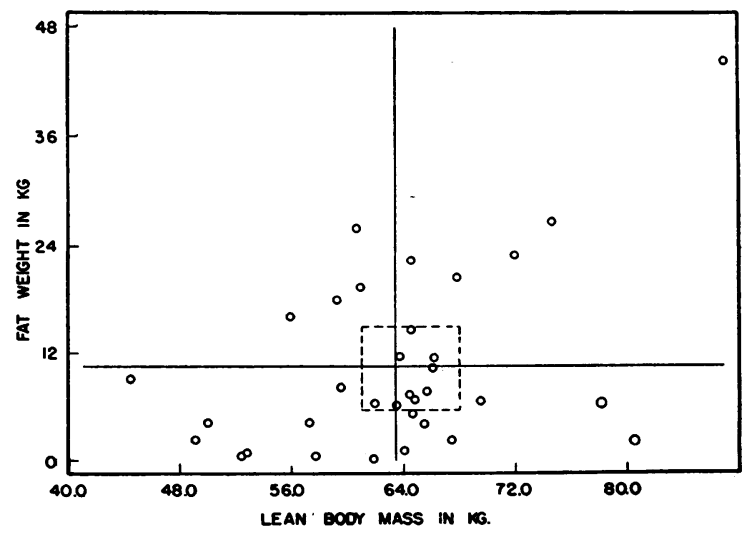

Fig. 3. The Relationship Between the Weight of Fat and the Lean Body Mass

The horizontal line is the mean of the fat weights and the vertical line is the mean of the fat-free weights. The box in the center encloses the "normal" group. 
TABLE V

The means and standard deviations of the arteriovenous oxygen difference $(A-V)$, the cardiac index (cardiac output per square meter of body surface) and the cardiac output in cc. per minute per kilogram of lean body mass along with body composition and anthropometric characteristics of five groups of differing body composition

\begin{tabular}{|c|c|c|c|c|c|}
\hline & \multirow{2}{*}{ Normal } & \multicolumn{4}{|c|}{ Anthropometric type } \\
\hline & & $\begin{array}{l}\text { Fat wt. low } \\
\text { L. B. M. low }\end{array}$ & $\begin{array}{l}\text { Fat wt. high } \\
\text { L. B. M. low }\end{array}$ & $\begin{array}{l}\text { Fat wt. high } \\
\text { L. B. M. high }\end{array}$ & $\begin{array}{l}\text { Fat wt. low } \\
\text { L. B. M. high }\end{array}$ \\
\hline $\begin{array}{l}\text { N } \\
\text { Age } \\
\text { Wt. of fat } \\
\text { Lean body mass } \\
\text { \% standard wt. } \\
\text { A-V } \\
\text { Cardiac index } \\
\text { C. O., cc./Kg. L. B. M. }\end{array}$ & $\begin{array}{c}9 \\
23.0 \pm 1.8 \\
9.3 \pm 2.9 \\
64.6 \pm 1.2 \\
107.1 \pm 7.9 \\
41.08 \pm 4.08 \\
3.05 \pm 0.32 \\
89.9 \pm 10.2\end{array}$ & $\begin{array}{c}8 \\
22.1 \pm 2.4 \\
2.8 \pm 2.6 \\
55.1 \pm 4.7 \\
87.6 \pm 10.3 \\
42.57 \pm 7.44 \\
2.98 \pm 0.42 \\
91.5 \pm 14.5\end{array}$ & $\begin{array}{c}4 \\
23.8 \pm 5.2 \\
19.7 \pm 4.1 \\
58.9 \pm 2.2 \\
121.0 \pm 9.45 \\
48.0 \pm 4.48 \\
2.43 \pm 0.15 \\
78.8 \pm 3.6\end{array}$ & $\begin{array}{c}5 \\
24.0 \pm 2.7 \\
27.4 \pm 9.9 \\
73.4 \pm 8.9 \\
142.1 \pm 19.3 \\
41.31 \pm 2.62 \\
2.8 \pm 0.30 \\
83.2 \pm 6.4\end{array}$ & $\begin{array}{c}7 \\
23.1 \pm 3.6 \\
4.3 \pm 2.0 \\
70.1 \pm 6.6 \\
104.2 \pm 10.8 \\
38.42 \pm 4.27 \\
3.14 \pm 0.25 \\
86.6 \pm 3.9\end{array}$ \\
\hline
\end{tabular}

measurement were used in a manner similar to that in Figure 3 to establish the quadrants. A normal group was chosen and the differences between the mean arteriovenous oxygen differences of the several groups were tested with the $t$ test. Significant differences were found between the same pairs of groups which are listed above. In addition, the "normal" group showed a mean arteriovenous oxygen difference which was significantly ( $5 \%$ level) higher than the group which was characterized by a large lean body mass per unit height and small fat weight per unit height.

Anthropometric groups were also defined by plotting the percentage of standard weight for age and height against the percentage of fat, a procedure employed by McCance and Widdowson (14). The quadrants were defined by the line following 100 per cent of standard weight and 9.8 per cent fat. The figure of 9.8 per cent fat is the percentage of fat of a man 22 years old where weight is standard for height and age (15). An alternative presentation involved plotting the percentage of standard weight against the percentage of standard fat for age and height. The latter figure was found by the use of the tables provided by Brozek (16). Both of these procedures allocate the men into groups whose members were: 1) underweight for height and with a less than normal percentage of fat, 2) overweight for height and with a greater than normal percentage of fat, and 3 ) overweight for height and with a less than normal percentage of fat. In each formulation a control group, clustered around the center of the diagram, was chosen. In each case, it was possible to show that the group which was fat and overweight had an arteriovenous oxygen difference which was significantly larger than the group which was overweight and lean.

\section{DISCUSSION}

The classification of body build used here depends entirely on the validity of the specific gravity method. The calculation of the percentage of body fat in an individual depends on knowing the density of the lean body mass. We have used the figure of 1.10, provided by Rathbun and Pace (10). The use of a single figure for the density of the lean body mass is obviously an approximation. Since bone has a density of 1.43 and all other tissues a density of the order of 1.066 , the important source of error is the variation in the fraction of bone in the lean body mass. The important relations are given in the following equation:

Equation 8. Per cent of fat

$$
=100\left[\frac{1}{D}\left(\frac{4.188}{0.6334+R}\right)-\left(\frac{4.562}{0.6334+R}\right)+1\right] \text {, }
$$

where $D$ is the observed density of the body and $\mathrm{R}$ is the fraction of wet bone in the lean body mass. A density of 1.10 for the lean body mass requires an $R$ value of 0.1214 . In a muscular man, who has a smaller value of $R$, the standard equation will overestimate the fat content of the body, whereas in the thin man, who has a value of $R$ larger than 0.1214 , the fat content will be underestimated. Reasonable estimates of the variation in the value of $\mathrm{R}$ indicates that the error due to this source is probably not greater than 3 to 4 per cent of the total body weight. This problem will be discussed in more detail elsewhere. 
It has been recognized by other investigators (17) that the lean body mass may be a better reference point than surface area for such biologically important functions as basal metabolism, blood volume, etc. This possibility has been confirmed by this investigation in the case of the cardiac output.

However, the advantage of the lean body mass over the surface area as a reference point in clinically normal men appears to depend entirely on the relationships between the arteriovenous oxygen difference and the body compartments. It is not the purpose of this paper to examine the relationships between the basal metabolic rate and the various body compartments. However, it should be mentioned that in this data the correlation between oxygen consumption and surface area was of the same order of magnitude as that between oxygen consumption and lean body mass.

No relationship was found between blood pressure measured intra-arterially and body size or composition. This is, of course, contrary to observations made on large groups using the sphygmomanometer (18) where it was shown that the blood pressure increased with increasing relative weight. It has been assumed that the blood pressure increased with fatness. Our failure to find an increase in blood pressure with obesity is not surprising in view of the recent demonstration that the cuff method overestimates the blood pressure in arms of large diameter and underestimates the blood pressure in arms of small diameter (19, 20). The group studied here is small and it is not possible to state that there is not a relation between blood pressure and degree of obesity. However, it is clear that if such a relation exists the increment of blood pressure per unit of fatness must be small.

Equation 7 makes it clear that certain anthropometric types have characteristic arteriovenous oxygen differences. Since the cardiac output is equal to the oxygen consumption divided by the arteriovenous difference, it follows that the basal cardiac output is not strictly proportional to the basal oxygen consumption in individuals with different body compositions. In addition, the significant differences between the cardiac indexes of different anthropometric groups presented in Table $\mathrm{V}$ demonstrates that the cardiac output is not strictly proportional to the surface area in the several anthropometric types.
It is apparent that the largest cardiac outputs per square meter of surface area and per cc. of oxygen consumption will be found in muscular (large lean body mass) individuals who have a relatively small fat content. Fatness per se does not necessarily mean that the basal cardiac output and cardiac work has been increased in proportion to the increase in surface area or oxygen consumption. Thus, those people with a relatively small lean body mass and a relatively large mass of fat will have cardiac outputs which are definitely less than that predicted from surface area or oxygen consumption. The person who has a large fat-mass which is superimposed on a large muscle-mass (lean body mass) may have a cardiac output nearly proportional to the surface area and to oxygen consumption.

The increasing arteriovenous oxygen difference associated with increasing amounts of fat on the body may well act as a protective mechanism since it reduces the cardiac work load below that which would exist if the cardiac output always remained proportional to the oxygen consumption. In this connection it is interesting to note that Smith and Willius (21) were able to find evidence of cardiac hypertrophy at autopsy in only 30 per cent of 52 obese patients who were selected because there was no evidence of heart failure or hypertension.

Finally, it should be kept in mind that the conclusions of this investigation apply strictly to young men in their twenties who are living in a university environment. Preliminary studies of middle-aged business men (22) have demonstrated that the arteriovenous oxygen difference changes markedly with age.

\section{SUMMARY AND CONCLUSIONS}

1. The basal cardiac outputs of 34 healthy male university students were determined by the acetylene technic and the values were corrected to direct Fick levels. The specific gravity of the body was determined by the water immersion method and the amount of body fat was estimated for all men.

2. It was found that the basal cardiac output was related to body weight by a correlation coefficient $(r)$ of 0.54 , to surface area by an $r$ of 0.60 , to the weight of lean body mass by an $r$ of 0.74 and finally to the weight of fat by an $r$ of 0.16 .

3. Intra-arterial blood pressure was measured 
on 20 of these men and basal cardiac work was calculated. The basal cardiac work was related to anthropometric measures of body mass and compartments in roughly the same manner as basal cardiac output. The coefficients of correlation relating basal cardiac work to body weight, surface area, weight of fat-free tissue and fat were found to be $0.50,0.55,0.76$, and 0.07 , respectively.

4. The arteriovenous oxygen difference was positively correlated with fat and negatively correlated with lean body mass. The arteriovenous oxygen difference predicted by a multiple regression equation using the weight of fat and the lean body mass as predictors was related to the observed arteriovenous oxygen difference by a coefficient of correlation of 0.63 .

5. It was shown that the basal cardiac output was not strictly proportional to surface area and oxygen consumption in certain anthropometric types.

\section{ACKNOWLEDGMENTS}

It is a pleasure to acknowledge the cooperation and assistance of Drs. Paul Winchell and Frederick de la Vega who helped collect some of the data; Mr. Kenneth Tiede and Mr. John White who performed much of the statistical analysis; Dr. Joseph. T. Anderson who was responsible for the derivation of Equation 8; and Mrs. Nedra Foster, administrative technologist, and Miss Laura Werner, technologist, whose patience and tireless attention to detail helped make this work possible.

\section{REFERENCES}

1. Du Bois, E. F., Basal Metabolism in Health and Disease. 3d ed., Lea and Febiger, Philadelphia, 1936, p. 256.

2. Rynearson, E. H., and Gastineau, C. F., Obesity. Charles C. Thomas, Springfield, 1949, p. 17.

3. Taylor, H. L., and Tiede, K., A comparison of the estimation of the basal cardiac output from a linear formula and the "cardiac index." J. Clin. Invest., 1952, 31, 209.

4. Brown, H. R., Jr., and Pearson, R., Demonstration of a positive relationship between cardiac output and oxygen consumption. Proc. Soc. Exper. Biol. \& Med., 1947, 65, 307.

5. Wertheimer, E., and Shapiro, B., The physiology of adipose tissue. Physiol. Rev., 1948, 28, 451.

6. Behnke, A. R., Feen, B. G., and Welham, W. C., The specific gravity of healthy men. J. A. M. A., 1942, 118, 495.

7. Chapman, C. B., Taylor, H. L., Borden, C., Ebert, R. V., and Keys, A., Simultaneous determinations of the resting arteriovenous oxygen difference by the acetylene and direct Fick methods. J. Clin. Invest., 1950, 29, 651.

8. Cournand, A., Baldwin, E. D., Darling, R. C., and Richards, D. W., Jr., Studies on intrapulmonary mixture of gases. IV. The significance of the pulmonary emptying rate and a simplified open circuit measurement of residual air. J. Clin. Invest., 1941, 20, 681.

9. Brozek, J., Henschel, A., and Keys, A., Effect of submersion in water on the volume of residual air in man. J. Appl. Physiol., 1949, 2, 240.

10. Rathbun, E. N., and Pace, N., Studies on body composition. I. The determination of total body fat by means of the body specific gravity. J. Biol. Chem., 1945, 158, 667.

11. Keys, A., Friedell, H. L., Garland, L. H., Madrazo, M. F., and Rigler, L. G., The roentgen kymographic evaluation of the size and function of the heart. Am. J. Roentgenol., 1940, 44, 805.

12. Bazett, H. C., Cotton, F. S., LaPlace, L. B., and Scott, J. C., The calculation of cardiac output and effective peripheral resistance from blood pressure measurements with an appendix on the size of the aorta in man. Am. J. Physiol., 1935, 113, 312.

13. Kleiber, M., Body size and metabolic rate. Physiol. Rev., 1947, 27, 511.

14. McCance, R. A., and Widdowson, E. M., A method of breaking down the body weights of living persons into terms of extracellular fluid, cell mass and fat and some applications of it to physiology and medicine. Proc. Roy. Soc. London, 1950, s.B., 138, 115.

15. Brozek, J., and Keys, A., Limitations of the "normal" body weight as a criterion of normality. Science, 1950, 112, 788.

16. Brozek, J. Changes of body composition of man during maturity and their nutritional complications. Federation Proc., 1952, 11, 784.

17. Behnke, A. R., Physiologic studies pertaining to deep sea diving and aviation, especially in relation to the fat content and composition of the body. Harvey Lect., 1941-42, 37, 198.

18. Rony, H. R., Obesity and Leanness. Lea and Febiger, Philadelphia, 1940, p. 227.

19. Ragan, C., and Bordley, J., III, The accuracy of clinical measurements of arterial blood pressure. With a note on the auscultatory gap. Bull. Johns Hopkins Hosp., 1941, 69, 504.

20. Thomson, A. E., and Doupe, J., Some factors affecting the auscultatory measurement of arterial blood pressures. Canad. J. Research, 1949, s.E., 27, 72.

21. Smith, H. L., and Willius, F. A., Adiposity of the heart: A clinical and pathological study of one hundred and thirty-six obese patients. Arch. Int. Med., 1933, 52, 911.

22. Taylor, H. L., Brozek, J., and Keys, A., Basal cardiac output in young and middle-aged men and its relation to body composition. J. Gerontol., 1951, 6, Supplement to No. 3, 156. 